\title{
Wavelet analysis of flame blowout of a liquid-fueled swirl burner with quarls
}

Viktor Józsa ${ }^{\text {a) }}$, Gergely Novotni ${ }^{\text {b) }}$

(Received:; Revised:; Accepted:)

Lean swirl combustion is the leading burner concept today, used in several steady-operating applications to ensure a wide operating range and low pollutant emissions. Approaching lean blowout is highly desired by design to achieve the lowest possible NOx emission. It was shown earlier that quarls could significantly extend the operating regime of liquid-fueled swirl burners. In the present study, the accompanying acoustic noise is evaluated by continuous wavelet transformation to show the effect of various quarl geometries on lean flame blowout. However, the desired flame shape of swirl burners is $\mathrm{V}$, straight flame, then a transitory regime can be observed before the developed $\mathrm{V}$-shaped flame by increasing the swirl number. If the axial thrust is excessive, blowout might occur in earlier stages. Presently, the characteristic bands before blowout were analyzed and evaluated at various quarl geometries, swirl numbers, and atomizing pressures. The latter parameter also acts as an axial thrust control to adjust the swirl number.

Primary subject classification: 21.3.2; Secondary subject classification: 12.1.5-6

\section{INTRODUCTION}

Nowadays, nearly $86 \%$ of the utilized energy is based on fossil fuels ${ }^{1}$. Since none of the renewable energy sources are currently able to replace fossil fuels entirely to achieve a sustainable economy, both renewable and fossil fuel combustion technologies should be developed in parallel. Therefore, fundamental goals should be set to make the results generally applicable in the future combustion systems regardless of the fuel type and its physical and chemical properties. This latter requirement is usually fulfilled by steady-operating combustion applications like industrial boilers, furnaces, and gas turbines where the combustion chamber temperature is above $1000 \mathrm{~K}^{2,3}$, and chain breaking occurs promptly. Hence, the atomic fuel composition becomes the governing factor of the process.

The present work focuses on the acoustics of a lean premixed burner which generally ensures a wide operating range and low pollutant emissions ${ }^{4}$. The leaner the air-fuel mixture is, the lower the $\mathrm{NO}_{\mathrm{X}}$ emission $^{5}$. Therefore, these burners operate rather close to the flame blowout where the operation is quasi-steady as various frequencies emerge which may lead to malfunction or serious system damage . $^{6}$ Consequently, knowing the conditions of safe operation near flame blowout allows us to design more efficient combustion systems with low pollutant emissions.

a) Budapest University of Technology and Economics, Faculty of Mechanical Engineering, Department of Energy Engineering, 1111 Budapest, Müegyetem rkp. 3, Hungary; email: jozsa@energia.bme.hu.

b) Budapest University of Technology and Economics, Faculty of Mechanical Engineering, Department of Energy Engineering, 1111 Budapest, Müegyetem rkp.3, Hungary; email: novigeri93@gmail.com. 
It is known that certain, system-related frequencies characterize combustion which decrease in the spectral space until blowout ${ }^{6}$. Hence, it seems a straightforward choice to perform a Fourier analysis on the time series signal ${ }^{7-10}$ of either pressure ${ }^{11}$ and/or $\mathrm{OH}^{* 12}$ or $\mathrm{CH}^{* 13-15}$ intensity. Usually, the presented characteristics in the technical literature are usually the result of operation at few measurement points on an extended time frame. This approach allows the accurate identification of the characteristic peaks using a wide time window for the Fourier transform. Nevertheless, the violent processes in a practical combustion chamber occur in a relatively short time frame, where not only detection and processing of the irregular phenomena should be performed but the actuation as well ${ }^{16}$. In numbers, this is roughly one second in the case of jet engines ${ }^{17}$.

The typical combustion-related frequencies close to blowout are located in the range of 100$1,500 \mathrm{~Hz}^{6,18}$ which allows the use of conventional microphones and pressure sensors for the detection of combustion irregularities. An early comprehensive paper on the favorable mathematical properties of the wavelet transform over Fourier transform was published in 1993 by Strang ${ }^{19}$ for media compression. Nair and Lieuwen compared various signal processing techniques of the blowout of piloted, swirl, and bluff body stabilized burners ${ }^{17}$ from which wavelet analysis turned to be the most attractive solution to capture flame blowout. Following this motivation, a wavelet analysis of the blowout of bluff body stabilized flame was performed by Chaudhuri and Cetegen ${ }^{20}$. Since shear-originated flow structures dominate non-swirl flames, the researchers were unable to find characteristic frequencies. In the case of highly intense shear flows, the skewness of the pressure waveform is an additional tool for noise analysis $^{21}$. Besides bluff bodies, quarls also increase the blowout stability of the flame ${ }^{22}$. However, the attached flame to the quarl wall leads to a shorter maintenance interval, it may significantly extend the operating range, up to $50 \%$ in the presently investigated configurations ${ }^{23}$.

The novelty of the present paper is the wavelet analysis of lean flame blowout events in the case of liquid fuel combustion, using the time series signal of a microphone. Even though the literature is rich in spectral analysis of lean blowout, these papers utilize mostly natural gas, and in a small portion, other gaseous alkanes. Consequently, the presence of atomization and evaporation in liquid fuel combustion already mean a notable contribution. Another point is the evaluation of a large number of setups in terms of atomizing pressure and flame stabilizing quarls, following the preceding work ${ }^{23}$ in lean flame blowout analysis. The third novel aspect is the use of continuous wavelet transform as an evaluation tool which is seldom used in the field of combustion. However, it was already proven that it is a powerful tool for the evaluation of signals with a wide range of frequencies present.

\section{MATERIALS AND METHODS}

The present section firstly discusses the continuous wavelet transform in Subsection 2.1, highlighting its mathematical differences from Fourier transform in the light of the typical composition of the combustion noise. The combustion-originated noise was polluted with the tonal components of the combustion air fan. Therefore, signal filtering had to be performed, and this procedure is explained in Subsection 2.2. Thirdly, the measurement setup is introduced in detail in Subsection 2.3, emphasizing liquid fuel atomization and its characteristics of the investigated burner, then swirl combustion and the observed flame shapes before blowout are discussed. 


\subsection{Wavelet transformation of combustion noise}

Wavelet transformation offers the opportunity to decompose the original signal by using almost arbitrary-shaped base functions, called wavelets, which have to be absolutely and square integrable ${ }^{24}$. Consequently, there is no need for window functions which is necessary for Fast Fourier transform and the related Short-time Fourier transform (STFT). In the present paper, Continuous wavelet transform (CWT) was used with the default Morse wavelet in the MATLAB software environment which was also used by Pawar et al. ${ }^{25}$. In general, a wavelet takes the following shape ${ }^{26}$ :

$$
\psi_{b a}(t)=\frac{1}{\sqrt{a}} \psi\left(\frac{t-b}{a}\right),
$$

where $\Psi(t)$ is the time-dependent function of the $\Psi$ mother wavelet. $b$ is the translation parameter which is responsible for moving the particular wavelet along the signal length. $a$ is the scale parameter that is responsible for maintaining the norm of unity to keep the energy content of the signal undisturbed. The CWT algorithm sweeps across the signal by varying $b$ with adapted $a$ value that exactly determines the maximum number of translation steps in a discrete, finite signal. Since $a$ stretches $\Psi$, the shorter wavelets provide a better temporal resolution. The resulting wavelet coefficient is calculated by Eq. (2):

$$
W_{\psi} x(b, a)=\int_{-\infty}^{\infty} x(t) \cdot \overline{\psi_{b a}(t)} \mathrm{d} t
$$

where $x(t)$ is the temporal signal, $W_{\Psi x}(b, a)$ is the wavelet coefficient with fixed $a$ and $b$ parameters. Overbar notes the complex conjugate. The result of a CWT is discussed in a translation-scale plane instead of the time-frequency plane which is reserved for the STFT. The formulation of Eq. (1) leads to the conclusion that CWT is a multiresolution analysis. This is mathematically connected to the uncertainty principle of Heisenberg which states that if the measurement of the momentum of a particle is more precise, the position is less certain. Hence, the area of a window in either a time-frequency or translation-scale plane is constant. Nevertheless, it is possible to adjust one side while the other will follow the change to result in the same area. STFT uses a fixed aspect ratio in the time-frequency space while CWT is characterized by narrow scales at low frequencies that decreases as $2^{n}$ up to the higher scales where the temporal projection of the window becomes narrow. Evidently, the result of a CWT analysis can be reproduced by STFT with multiple window sizes from which only one frequency-time slice is taken from each run and finally put together. The match will be only qualitative since the basis functions differ, and the harmonic functions fail to meet the mathematical criteria of a wavelet. A comparison and evaluation of the two methods in the case of the presently used measurement configuration is discussed elsewhere ${ }^{27}$.

Combustion is usually characterized by a broadband noise spectrum ${ }^{9}$ while certain frequencies related to the flow field structure emerge and clearly identifiable ${ }^{7,28}$. Since these narrow-band frequencies are located at a few hundred $\mathrm{Hz}$ while the broadband roar is located at few $\mathrm{kHz}$, the multiresolution property of the CWT fits excellently for combustion noise analysis. For applications featuring principally tonal components at both high and low frequencies, the more robust and computationally cheaper STFT is recommended.

\subsection{Filtering tonal components with CWT}

The present paper focuses only on flame blowouts which are evaluated from $2^{14}$ samples. The sampling frequency was $12 \mathrm{kHz}$, therefore, it corresponds to the temporal window size of $1.365 \mathrm{~s}$. These 
cuts were chosen to show the last second of combustion, then the noise during the lean flame blowout. Nevertheless, the measurement system also affects the spectrum which should be filtered to allow the analysis of the isolated combustion process. In the present case, the frequency-controlled combustion air fan polluted the spectrum most significantly when the lean blowout occurred at high air flow rates. In such setups, the following frequency components needed filtering: rotational speed (x1), harmonics of the rotational speed (x2-x4), a single blade pass of the six-bladed impeller (x6), and its harmonics. Where these components were found to be dominant, the corresponding CWT coefficients were all zeroed in the entire length of the analyzed signal section. The filtering procedure is shown in Fig. 1. The white dashed line is the cone of influence. The edge effect might notably bias the results outside of this regime. If the investigated phenomenon is dominated by well-defined peaks, a wavelet-based de-noising is also a viable approach $^{29}$.

The removed frequency center bands of the top scalogram in Fig. 1 were 35, 105, and $840 \mathrm{~Hz}$. The first one meant no harm to the data; its exclusion was straightforward. However, the second and third bands interacted with the combustion noise since their amplitude notably varied over time. Consequently, the use of these filters inevitably leads to the loss of otherwise valuable information. Unfortunately, the combustion air fan-related frequencies could not be efficiently filtered alone since its amplitude varies temporally due to the stochastic nature of combustion. In order to isolate the spectral characteristics of the flame, these components were eliminated to get a better representation of the process. All the frequency filtering will always be noted over the course of the paper.

The above-mentioned frequencies were filtered out, nevertheless, they were the only steady, clear structures in the signal. Hence, the scalogram is left with high-amplitude CWT coefficients which fall into a certain frequency regime which can be even $1 \mathrm{kHz}$ wide, and the coefficients show a rather fluctuating behavior as a temporal function which is the combustion roar ${ }^{9}$. This behavior is originated from the complex vortex-heat release-acoustics system as these three phenomena are continuously interacting with each other in a highly nonlinear way ${ }^{6,30}$. In the present case, this is the following. The liquid fuel is atomized by an airblast atomizer which creates a small but rather intense shear layer which becomes a particle-laden flow structure. The vaporized fuel hence rapidly mixes with the atomizing air, and when the conditions of ignition are met, reactions involving $\mathrm{H}$ and $\mathrm{OH}$ take place promptly compared to the fluid dynamical time scale ${ }^{31}$. As the droplets follow an atomizer-characteristic distribution function $^{32}$, the start of the ignition varies with the droplet evaporation time. In addition, the local equivalence ratio also changes depending on the fuel quantity entrapped in various vortex structure sizes which leads to fluctuations in the heat release. As all these phenomena occur in a shear layer, the system becomes rather complex and involves few magnitudes of scales. This is the reason why combustion noise has stochastic spectral characteristics. The rapidly expanding combusting gas mixture in the shear layer increase the noise of the cold flow by around $20 \mathrm{~dB}$ in the present case.

\subsection{The measurement system}

Figure 2 shows the cross-section of the investigated burner. The fuel flows in a $0.4 \mathrm{~mm}$ central pipe at $3.4 \mathrm{~m} / \mathrm{s}$ whilst the high-velocity atomizing air discharges from a concentrical annular orifice, which has $1.4 \mathrm{~mm}$ outer and $0.8 \mathrm{~mm}$ inner diameter, at $200-380 \mathrm{~m} / \mathrm{s}$, depending on the atomizing gauge pressure, $p_{g}$. The resulting high relative velocity violently disintegrates the liquid jet into ligaments then droplets. The combustion air enters the mixing tube of $26.8 \mathrm{~mm}$ diameter and $75.5 \mathrm{~mm}$ length from the 
atomizer tip through four circular holes and fifteen rectangular $45^{\circ}$ vanes which swirl the inlet flow. The thermal power was $15 \mathrm{~kW}$ in all the test cases, utilizing standard diesel oil (EN 590:2014). These conditions resulted in fully turbulent combustion during all the measurement cases.

In atomization for combustion purposes, the surface-to-volume diameter, $S M D$, is of primary importance. Equation (3) was used for its estimation ${ }^{33}$ :

$$
S M D=0.66 d_{0} W e_{A}^{-0.5}(1+1 / A L R),
$$

where $d_{0}=0.4 \mathrm{~mm}$ is the liquid jet diameter, $W e_{A}$ is the Weber number using the density and velocity of atomizing air, and $A L R$ is the air-to-liquid mass flow ratio of the atomizer. Results at $p_{g}=0.3,0.6$, and $1.6 \mathrm{bar}$ are in the focus of the present paper, however, $p_{g}=0.8,1.1$, and 2.3 bar showed similar characteristics. Table 1 summarizes the relevant parameters of the atomization process. The evaporation of liquid drops inside the mixing tube was calculated elsewhere ${ }^{34,35}$. Note that small droplets are slightly affected by both convection and radiation due to their low inertia and surface area, respectively ${ }^{36}$.

Figure 3 shows the test rig. Only the key operating parameters highlighted here, a more detailed description along with uncertainties were discussed in earlier works ${ }^{37,38}$. A fan delivered the combustion air, and an electrical heater increased its temperature up to $400{ }^{\circ} \mathrm{C}$ prior to the burner. The combustion took place in the open atmosphere; hence, only the primary air-to-fuel equivalence ratio, $\lambda$, was controlled. An SVAN 971 Class 1 noise analyzer was used for recording the combustion noise at $12 \mathrm{kHz}$ sampling rate. The sensitivity of the microphone is $28.74 \mathrm{mV} / \mathrm{Pa}$ and was calibrated with an SV33 calibrator which generates $114 \mathrm{~dB}$ at $1 \mathrm{kHz}$ and complies with the IEC 60942:2003 standard. The microphone was placed $1 \mathrm{~m}$ away from the burner axis with positioning its height to the burner lip. It was turned out earlier by using a microphone array system that the investigated combustion noise at $1 \mathrm{~m}$ distance can be considered as an acoustically compact source.

The principal dimensions of the quarls, which were placed on the burner lip, are shown in Fig. 4. The half cone angle, $\Theta$, was varied between $0^{\circ}$ and $60^{\circ}$ in $15^{\circ}$ steps. Here, $0^{\circ}$ means an extension for the mixing tube, i.e., its length became $75.5+17 \mathrm{~mm}$. During the measurements, the plain burner, referred to as baseline, was also investigated besides the five quarls.

To characterize swirling flows, including swirling flames, the swirl number, $S$, is often used, defined by Eq. $(4)^{39}$ :

$$
S=G_{\varphi} /\left(G_{x} \cdot R\right),
$$

where $G_{\varphi}$ is the axial flux of the angular momentum, $G_{x}$ is the axial thrust, and $R$ is the radius of the mixing tube. Depending on $S$, straight and V-shaped flames were observed, shown in Fig. 5. Note that the geometric swirl number was calculated here, based on the inlet conditions of the burner.

A straight flame was typically present until $S=0.53$, and a fully $\mathrm{V}$-shaped flame was developed by reaching $S=0.82$. The operation between them, i.e., $0.53<S<0.82$, showed a transitory behavior, where both flame shapes were observed. Since turbulence is a broadband excitation source which is continuously present, the flame randomly altered between the mentioned two shapes. However, the average ratio of the occurring shapes is linearly proportional to the distance of the current operating point from the mentioned stability limits in terms of $S$.

The measurement procedure was the following. After installing a quarl and setting the atomizing pressure, the combustion air flow rate was increased from $10 \mathrm{~m}^{3} / \mathrm{h}$ until blowout. Since the burner has fixed swirl vanes, $S$ increased with $\lambda$; this relation could not be decoupled in the present case. After the 
lean flame blowout, a higher atomizing pressure was set, the combustion air flow rate was reset to 10 $\mathrm{m}^{3} / \mathrm{h}$, then the measurement was repeated until the next blowout. Finally, the quarl was changed, and the procedure detailed above was repeated again. The maximum uncertainty of $S$ and $\lambda$ were $4.43 \%$, and $2.25 \%$, respectively. This holds only for the primary $\lambda$, which is included in Tables $2-4$, as the effect of air entrainment was not controlled.

\section{RESULTS AND DISCUSSION}

In lean swirl combustion, V-shaped flame is usually desired, however, this state has to be reached. Since the high-velocity atomizing jet significantly reduces $S$, the flame blowout occurred in all straight, transitory, and V-shaped flame forms, depending on the setup. Due to the low initial combustion air flow rate, a straight flame was observed at the beginning of all measurement setups. Firstly, blowout at $p_{g}=0.3 \mathrm{bar}$ is discussed. The corresponding operating parameters at various quarl geometries are shown in Table 2. Since $p_{g}=0.3$ bar is a design point of the investigated burner, V-shaped flames were observed prior to the blowout event. The corresponding $S$ and $\lambda$ parameters were relatively close to each other, allowing the evaluation of the effect of various quarls on combustion noise. The corresponding CWTs of blowout are shown in Fig. 6.

In V-shaped operation, typically, bands at 225 and $500 \mathrm{~Hz}$ dominate the acoustic field which are related to the recirculation zones inside and outside of the $\mathrm{V}$. The number of dominant modes is in accordance with the recent results of Noiray and Denisov ${ }^{7}$. However, the spectrum contains notable frequencies both below and above the mentioned two regimes, especially in the case of the $0^{\circ}, 45^{\circ}$ and $60^{\circ}$ quarls. The corresponding CWT coefficients of the two latter configurations are double of that of the other setups, shown in Fig. 6. INcreased combustion air reduces the overall flame propagation velocity and the shear between the combustion air flow and the atomizing air jet. Hence, the $15^{\circ}$ and $30^{\circ}$ cases are quieter than the others. Regardless of the similar swirl number of the $0^{\circ}$ and the $60^{\circ}$ quarls, a $100 \mathrm{~Hz}$ frequency component emerges in the former case prior blowout, while the latter one contains notable peaks at $1 \mathrm{kHz}$. Therefore, the appearance of low-frequency components is not a general trend which always precedes the lean flame blowout. Note that in the former case only the $75.5 \mathrm{~mm}$ long straight part of the mixing tube of the burner was supplemented by a $17 \mathrm{~mm}$ long tube which does not affect notably the scalogram compared to the baseline variant. The near $1 \mathrm{kHz}$ regime also contains notable information in all cases. However, the firm interaction with the combustion air fan polluted this region in the case of the $15^{\circ}$ quarl. Consequently, filtering was necessary which lead to information loss. Nevertheless, the removal of the external noise near 35 and $105 \mathrm{~Hz}$ by zeroing the CWT coefficients did not harm the scalograms.

Table 3 summarizes the conditions of the flame blowout at $p_{g}=0.6$ bar. According to Table 1 , the resulting mean droplet size reduces by $25 \%$ compared to $p_{g}=0.3$ bar. The blowout here occurred in the transitory shape in the baseline burner configuration while V-shaped flame characterized the rest of the setups. Due to the increased axial thrust by the elevated $p_{g}$, the swirl numbers all decreased, and the blowout took place at lower $\lambda$ in the baseline case. The filtered frequencies were similar to those of Table 2. However, the $840 \mathrm{~Hz}$ component did not need filtering in the case of the $15^{\circ}$ quarl, unlike at $p_{g}=0.3$ bar. Therefore, the information loss due to filtering was negligible at this atomizing pressure.

The transitory operation in the case of the baseline burner included notable frequency components between 3 and $4 \mathrm{kHz}$ since this mode is characterized by both straight and V-shaped flames, shown in 
Fig. 7. Nevertheless, a spectral analysis allows the separation of the various patterns in this flame shape in the time domain that can be either CWT or STFT. The duration of one shape varied between $0.05-0.3$ seconds. Due to the rapid changes in the flow field, the magnitude scale exceeds that of all other cases at this atomizing pressure. This is likely caused by a subcritical Hopf bifurcation ${ }^{40,41}$ which require further investigations, therefore, it is not discussed in the present paper. The $0^{\circ}$ quarl showed characteristic frequencies below $100 \mathrm{~Hz}$ again. At $p_{g}=0.6 \mathrm{bar}$, one band started to dominate the spectrum in all cases from the above-mentioned regimes around either 225 or $500 \mathrm{~Hz}$, depending on the setup. Regardless of this change in the frequency domain, the time evolution of the dominant components is still spectacular. Again, the $15^{\circ}$ quarl was the quietest since its operation lies close to the theoretical lean combustion limit which is nearly $\lambda=2$ in case of hydrocarbon fuels ${ }^{42}$. Frequency components near $1 \mathrm{kHz}$ were uniformly faded to the background noise, compared to that in Fig. 6. Repeatedly, the $45^{\circ}$ and $60^{\circ}$ quarls produced higher noise than the other configurations except the transitory operation of the baseline burner setup. The CWT coefficient trends are relatively close in the case of Figs. 6 and 7, therefore, the blowout at $p_{g}=1.6$ bar is evaluated in the following.

The key operating parameters at $p_{g}=1.6$ bar were summarized in Table 4 , similar to the previous cases. Blowout at V-shaped operation characterizes only the $15^{\circ}$ and $30^{\circ}$ quarls due to the significantly increased thrust of the atomizing free jet. The superiority of these quarls is evident over the other configurations $^{23}$. The blowout of the rest of the configurations occurred even in straight flame shape besides the transitory regime. The average droplet size at this atomizing pressure is $66 \%$ lower in diameter compared to that at $p_{g}=0.3$ bar, which means rapid evaporation and mixing with the combustion air. Therefore, the ignition delay reduces, and the flame moves back to the mixing tube. Since the strong shear caused by the atomizing free jet superimposes to the above phenomenon, this condition results in a dramatic increase in combustion noise.

The higher CWT coefficients spectacularly mark the noisier operation, shown in Fig. 8. Regardless that straight flame was observed prior blowout, only the $0^{\circ}$ quarl shows notable amplitudes in the $3-$ $4 \mathrm{kHz}$ frequency regime. The baseline burner configuration seems to show a behavior similar to the $p_{g}=0.6$ bar case which is typical for a transitory flame regime. This phenomenon explains the reason of blowout. The precessing vortex core starts to breakdown, and the recirculation zones corresponding to the V-shaped operation start to form. However, this structure above the burner lip was blown out in few seconds by the significant momentum at the center, generated by the atomizing free jet. Similarly, the transitory shape was observed before the blowout of the flame in the case of the $45^{\circ}$ quarl, but no outstanding-amplitude high-frequency components are present in the spectrum of the last second of combustion. The formation of recirculation zones was disrupted by the atomizing jet, and when the flame was about to reach the fully V-shaped operation, the jet has blown the flame out. Nevertheless, the $60^{\circ}$ quarl showed the expected characteristics of the transitory regime based on observation. Compared to the previous cases, both the $15^{\circ}$ and $30^{\circ}$ quarls showed similar behavior in the spectrum to the previous cases, only the amplitude of the signal increased due to the more intensive shear caused by the atomizing jet.

\section{CONCLUSIONS}

Lean flame blowout of a $15 \mathrm{~kW}$ atmospheric, liquid-fueled lean premixed swirl burner was investigated in the present paper by using the continuous wavelet transform on the acoustic signal at 
blowout. The following parameters were varied: half cone angle of the installed quarl, atomizing pressure, and air-to-fuel equivalence ratio. Due to the fixed swirl vanes, the swirl number was not independent of the equivalence ratio. Based on the results, the following conclusions were derived:

- Combustion noise incorporates characteristic bands instead of characteristic frequencies. Moreover, their time evolution also significant which can be appropriately analyzed by continuous wavelet transform.

- Frequency components preceding or predicting flame blowout of swirl combustion cannot be generalized as blowout can occur in both straight and transitory regimes besides the V-shaped flame. Therefore, the disappearing high-frequency bands are not necessarily occurring before the blowout.

- The $15^{\circ}$ and $30^{\circ}$ quarls showed superior stability and the flame was blown out at similar spectra regardless of the atomizing pressure. The similar geometries of the baseline burner and the $0^{\circ}$ quarl showed similar blowout characteristics in terms of maximum equivalence ratio and typical appearing bands in the scalogram. However, the $0^{\circ}$ quarl featured a strong noise in the $3-4 \mathrm{kHz}$ regime at $p_{g}=0.6$ bar. Since the $45^{\circ}$ and $60^{\circ}$ quarls do not have an attached flame to their wall, their behavior at blowout requires further investigations with high-frequency imaging techniques.

\section{ACKNOWLEDGMENTS}

This paper was supported by the National Research, Development and Innovation Fund of Hungary, project №. OTKA-FK 124704, New National Excellence Program of the Ministry of Human Capacities project №. ÚNKP-18-4-BME-195 and №. ÚNKP-17-2-I, Artificial Intelligence research area of Budapest University of Technology and Economics (BME FIKP-MI), and the János Bolyai Research Scholarship of the Hungarian Academy of Sciences.

\section{REFERENCES}

1. Abas N, Kalair A, Khan N. Review of fossil fuels and future energy technologies. Futures. 2015;69:31-49. doi:10.1016/j.futures.2015.03.003

2. Filimonova E, Bocharov A, Bityurin V. Influence of a non-equilibrium discharge impact on the low temperature combustion stage in the HCCI engine. Fuel. 2018;228:309-322. doi:10.1016/j.fuel.2018.04.124

3. Liu X, Kokjohn S, Li Y, Wang H, Li H, Yao M. A numerical investigation of the combustion kinetics of reactivity controlled compression ignition (RCCI) combustion in an optical engine. Fuel. 2019;241:753766. doi:10.1016/j.fuel.2018.12.068

4. Lefebvre AH, Ballal DR. Gas Turbine Combustion. third. Boca Raton: CRC Press; 2010. doi:10.1002/1521-3773(20010316)40:6<9823::AID-ANIE9823>3.3.CO;2-C

5. Correa SM. A Review of NOx Formation Under Gas-Turbine Combustion Conditions. Combust Sci Technol. 1993;87(1-6):329-362. doi:10.1080/00102209208947221

6. Huang Y, Yang V. Dynamics and stability of lean-premixed swirl-stabilized combustion. Prog Energy Combust Sci. 2009;35(4):293-364. doi:10.1016/j.pecs.2009.01.002

7. Noiray N, Denisov A. A method to identify thermoacoustic growth rates in combustion chambers from dynamic pressure time series. Proc Combust Inst. 2017;36(3):3843-3850. doi:10.1016/j.proci.2016.06.092 
8. Khalil AEE, Gupta AK. Acoustic and heat release signatures for swirl assisted distributed combustion. Appl Energy. 2017;193:125-138. doi:10.1016/j.apenergy.2017.02.030

9. Strahle WC. Combustion noise. Prog Energy Combust Sci. 1978;4:157-176. doi:10.1016/03601285(78)90002-3

10. Ezhil Kumar PK, Mishra DP. Combustion noise characteristics of an experimental 2D trapped vortex combustor. Aerosp Sci Technol. 2015;43:388-394. doi:10.1016/j.ast.2015.03.014

11. Karlis E, Hardalupas Y, Taylor AMKP. Experimental characterization of intermittency of thermoacoustic instability in a swirl stabilized combustor. Proc 8th Eur Combust Meet. 2017:523-528.

12. Hayashi Y, Funatsu M, Kobayashi H, Gotoda H. Nonlinear analysis on dynamical motion of combustion instability in a laboratory-scale gas turbine model combustor. Proc 8th Eur Combust Meet. 2017:25052507.

13. Barbosa S, Scouflaire P, Ducruix S. Time resolved flowfield, flame structure and acoustic characterization of a staged multi-injection burner. Proc Combust Inst. 2009;32 II:2965-2972. doi:10.1016/j.proci.2008.06.139

14. Sampath R, Chakravarthy SR. Investigation of intermittent oscillations in a premixed dump combustor using time-resolved particle image velocimetry. Combust Flame. 2016;172:309-325. doi:10.1016/j.combustflame.2016.06.018

15. Idahosa U, Basu S, Miglani A. System Level Analysis of Acoustically Forced Nonpremixed Swirling Flames. J Therm Sci Eng Appl. 2014;6(3):1-15. doi:10.1115/1.4027297

16. Ballester J, García-Armingol T. Diagnostic techniques for the monitoring and control of practical flames. Prog Energy Combust Sci. 2010;36(4):375-411. doi:10.1016/j.pecs.2009.11.005

17. Nair S, Lieuwen T. Acoustic Detection of Blowout in Premixed Flames. J Propuls Power. 2005;21(1):3239. doi:10.2514/1.5658

18. Singh A V., Yu M, Gupta AK, Bryden KM. Thermo-acoustic behavior of a swirl stabilized diffusion flame with heterogeneous sensors. Appl Energy. 2013;106:1-16. doi:10.1016/j.apenergy.2013.01.044

19. Strang G. Wavelet transforms versus fourier transforms. Bull Am Math Soc. 1993;28(2):288-305. doi:10.1090/S0273-0979-1993-00390-2

20. Chaudhuri S, Cetegen BM. Blowoff characteristics of bluff-body stabilized conical premixed flames with upstream spatial mixture gradients and velocity oscillations. Combust Flame. 2008;153(4):616-633. doi:10.1016/j.combustflame.2007.12.008

21. Gee KL, Neilsen TB, Wall AT, Downing JM. Propagation of crackle-containing jet noise from highperformance engines. Noise Control Eng J. 2016;64(1):1-12. doi:10.3397/1/376354

22. Mansour MS, Elbaz AM, Samy M. The stabilization mechanism of highly stabilized partially premixed flames in a concentric flow conical nozzle burner. Exp Therm Fluid Sci. 2012;43:55-62. doi:10.1016/j.expthermflusci.2012.03.017

23. Józsa V, Kun-Balog A. Effect of diffusers on the blowout stability and emission of pollutants of a liquid fueled swirl burner. J Eng Gas Turbines Power. January 2018. doi:10.1115/1.4039056

24. Chui CK. An Introduction to Wavelets. 1st ed. Academic Press; 1992.

25. Pawar SA, Sujith RI, Emerson B, Lieuwen T. Characterization of forced response of density stratified reacting wake. Chaos. 2018;28(2). doi:10.1063/1.5006453

26. Chan AK, Liu SJ. Wavelet Toolware: Software for Wavelet Training. San Diego: Academic Press; 1998. 
27. Novotni GI, Józsa V. Determination of the minimal acoustic signal length for fast-acting control of a liquidfueled turbulent swirl burner by Wavelet and Fourier transform. In: Proceedings of the 9th European Combustion Meeting. Lisbon; 2019. http://real.mtak.hu/92816/.

28. Durox D, Moeck JP, Bourgouin JF, et al. Flame dynamics of a variable swirl number system and instability control. Combust Flame. 2013;160(9):1729-1742. doi:10.1016/j.combustflame.2013.03.004

29. Khan T, Ramuhalli P, Raveendra ST, Zhang W. Denoising and regularization in NAH for turbomachinery noise source reconstruction. Noise Control Eng J. 2009;58(1):93-103. doi:10.3397/1.3244595

30. Lieuwen T. Unsteady Combustor Physics. New York, NY: Cambridge University Press; 2012. doi:10.1017/CBO9781139059961

31. Maas U, Pope SB. Simplifying chemical kinetics: Intrinsic low-dimensional manifolds in composition space. Combust Flame. 1992;88(3-4):239-264. doi:10.1016/0010-2180(92)90034-M

32. Urbán A, Józsa V, András Urbán, Viktor Józsa, Urbán A, Józsa V. Investigation of fuel atomization with density functions. Period Polytech Mech Eng. 2018;62(1):33-41. doi:10.3311/PPme.11312

33. Urbán A, Zaremba M, Malý M, Józsa V, Jedelský J. Droplet dynamics and size characterization of highvelocity airblast atomization. Int $J$ Multiph Flow. 2017;95:1-11. doi:10.1016/j.ijmultiphaseflow.2017.02.001

34. Józsa V, Csemány D. Evaporation of renewable fuels in a lean premixed prevaporized burner. Period Polytech Mech Eng. 2016;60(2):82-88. doi:10.3311/PPme.8564

35. Csemány D, Józsa V. Fuel Evaporation in an Atmospheric Premixed Burner: Sensitivity Analysis and Spray Vaporization. Processes. 2017;5(4):80. doi:10.3390/pr5040080

36. Lefebvre AH, McDonell VG, Arthur H. Lefebvre VGM. Atomization and Sprays. Second. Boca Raton, FL, FL: CRC Press; 2017.

37. Kun-Balog A, Sztankó K. Reduction of pollutant emissions from a rapeseed oil fired micro gas turbine burner. Fuel Process Technol. 2015;134(x):352-359. doi:10.1016/j.fuproc.2015.02.017

38. Józsa V, Kun-Balog A. Stability and emission analysis of crude rapeseed oil combustion. Fuel Process Technol. 2017;156:204-210. doi:10.1016/j.fuproc.2016.11.004

39. Beér JM, Chigier NA. Combustion Aerodynamics. London: Robert E. Krieger Publishing Company, Inc.; 1972.

40. Boujo E, Denisov A, Bonciolini G, et al. Flame dynamics intermittency in the bi-stable region near a subcritical hopf bifurcation. Proc ASME Turbo Expo. 2017;Part F1300(June):1-6. doi:10.1115/GT201764943

41. Kabiraj L, Sujith RI. Nonlinear self-excited thermoacoustic oscillations: intermittency and flame blowout. J Fluid Mech. 2012;(August 2015):1-22. doi:10.1017/jfm.2012.463

42. Glassman I, Yetter R. Combustion. 4th ed. Burlington: Academic Press; 2008. 
Table 1-Principal operating parameters of atomization at various atomizing gauge pressures.

\begin{tabular}{cccc}
\hline$p_{\boldsymbol{g}}[\mathbf{b a r}]$ & $\boldsymbol{S M D}[\boldsymbol{\mu m}]$ & $\boldsymbol{W e}_{\boldsymbol{A}}[-]$ & $\boldsymbol{A L R}[-]$ \\
\hline 0.3 & 21.6 & 511,041 & 0.78 \\
0.6 & 13.4 & 889,566 & 1.1 \\
1.6 & 7.4 & $1,692,580$ & 1.73 \\
\hline
\end{tabular}


Table 2-Blowout conditions at $p_{g}=0.3$ bar.

\begin{tabular}{ccccc}
\hline quarl & Shape & $\boldsymbol{S}[-]$ & $\lambda[-]$ & Filter $[\mathrm{Hz}]$ \\
\hline baseline & $\mathrm{V}$ & 1.15 & 1.75 & - \\
$0^{\circ}$ & $\mathrm{V}$ & 1.14 & 1.73 & - \\
$15^{\circ}$ & $\mathrm{V}$ & 1.26 & 2.16 & $35,105,840$ \\
$30^{\circ}$ & $\mathrm{V}$ & 1.23 & 2.01 & 31,93 \\
$45^{\circ}$ & $\mathrm{V}$ & 1.19 & 1.85 & 29 \\
$60^{\circ}$ & $\mathrm{V}$ & 1.14 & 1.72 & 105 \\
\hline
\end{tabular}


Table 3-Blowout conditions at $p_{g}=0.6$ bar.

\begin{tabular}{ccccc}
\hline quarl & Shape & $\boldsymbol{S}[-]$ & $\boldsymbol{\lambda}[-]$ & Filter $[\mathbf{H z}]$ \\
\hline baseline & Transitory & 0.76 & 1.50 & - \\
$0^{\circ}$ & $\mathrm{V}$ & 0.90 & 1.78 & - \\
$15^{\circ}$ & $\mathrm{V}$ & 1.01 & 2.04 & 33,98 \\
$30^{\circ}$ & $\mathrm{V}$ & 1.03 & 2.11 & 34,100 \\
$45^{\circ}$ & $\mathrm{V}$ & 0.95 & 1.88 & 29 \\
$60^{\circ}$ & $\mathrm{V}$ & 0.84 & 1.65 & 105 \\
\hline
\end{tabular}


Table 4-Blowout conditions at $p_{g}=1.6$ bar.

\begin{tabular}{ccccc}
\hline quarl & Shape & $\boldsymbol{S}[-]$ & $\boldsymbol{\lambda}[-]$ & Filter $[\mathbf{H z}]$ \\
\hline baseline & Straight & 0.45 & 1.54 & - \\
$0^{\circ}$ & Straight & 0.47 & 1.57 & - \\
$15^{\circ}$ & V & 0.69 & 2.09 & - \\
$30^{\circ}$ & V & 0.69 & 2.09 & - \\
$45^{\circ}$ & Transitory & 0.52 & 1.70 & 25,102 \\
$60^{\circ}$ & Transitory & 0.44 & 1.50 & - \\
\hline
\end{tabular}




\section{List of Figure Captions}

Fig. 1-CWT of a signal piece before (top) and after filtering (bottom).

Fig. 2-Section of the investigated burner.

Fig. 3-The combustion test rig.

Fig. 4-Principal dimensions of the applied quarls.

Fig. 5-Straight (left) and V-shaped flame (right).

Fig. 6-CWT of the flame blowout at $p_{g}=0.3$ bar with various quarls.

Fig. 7-CWT of the flame blowout at $p_{g}=0.6$ bar with various quarls.

Fig. 8-CWT of the flame blowout at $p_{g}=1.6$ bar with various quarls. 

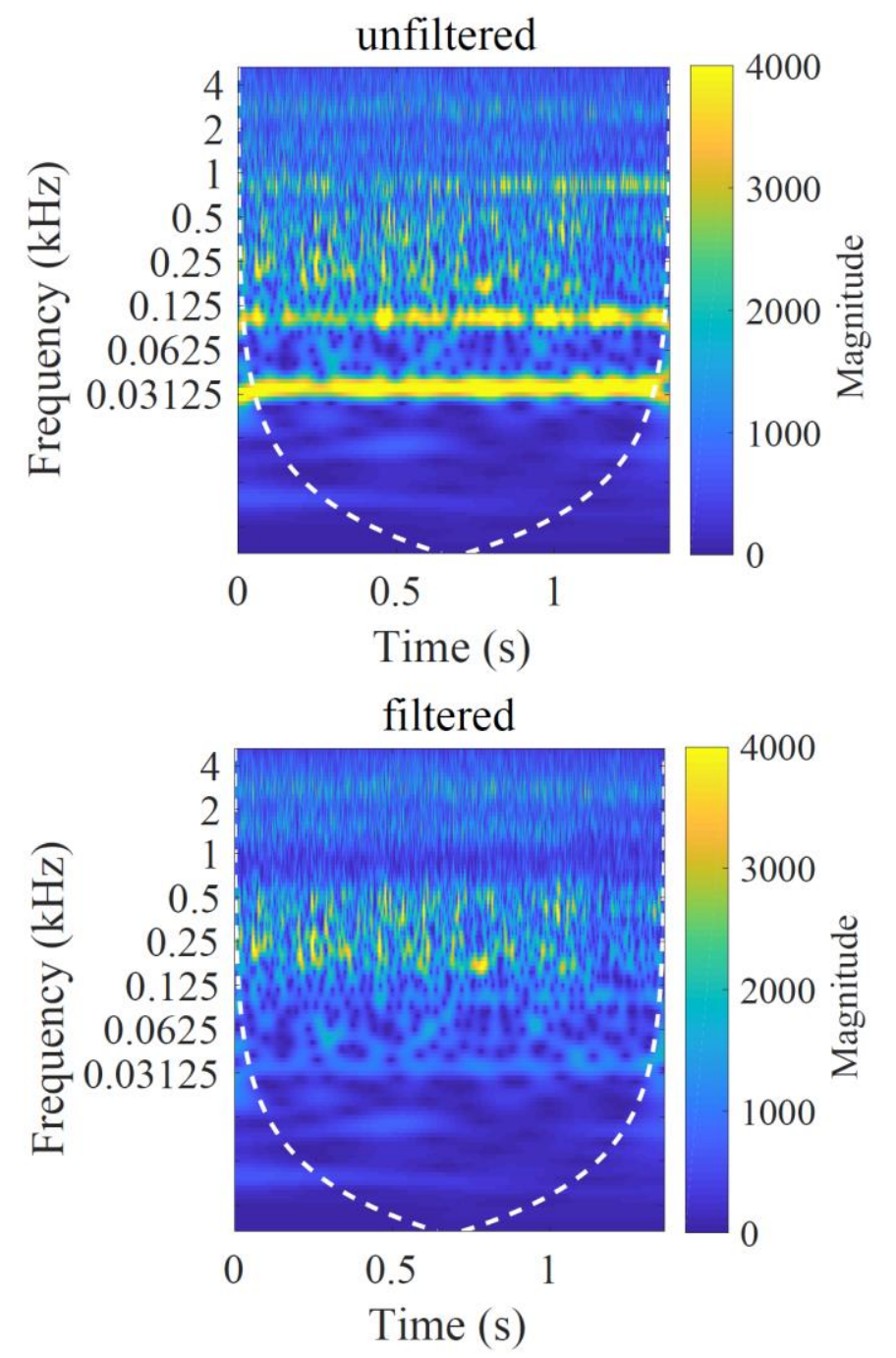

Fig. 1-CWT of a signal piece before (top) and after filtering (bottom). 


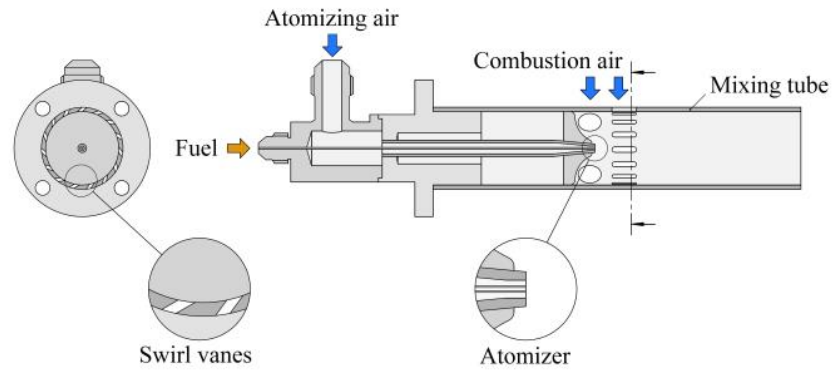

Fig. 2-Section of the investigated burner. 


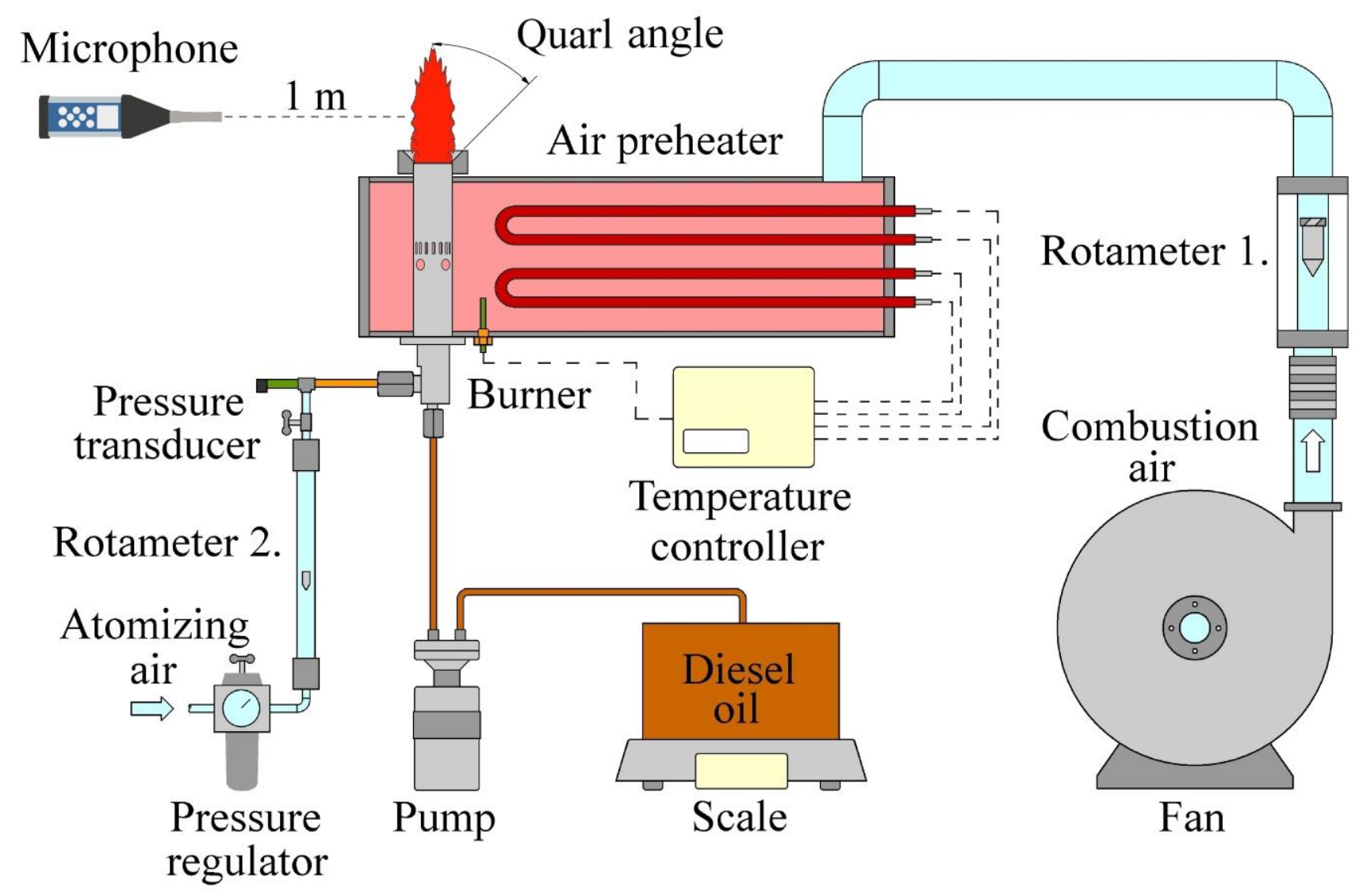

Fig. 3-The combustion test rig. 


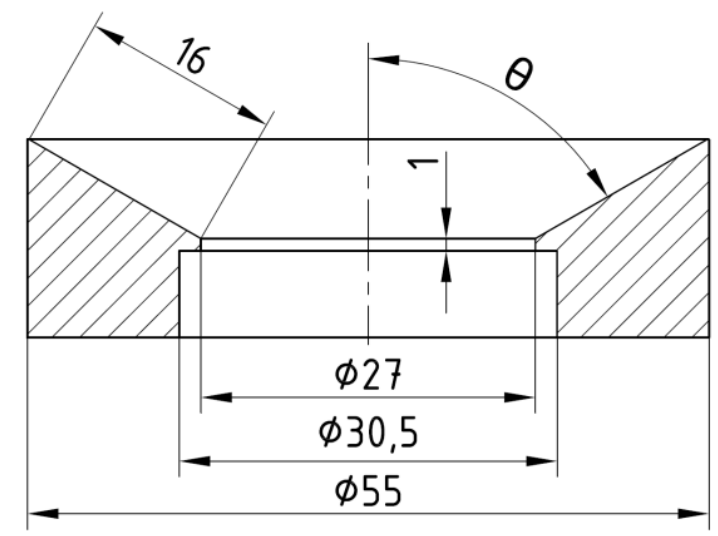

Fig. 4-Principal dimensions of the investigated quarls. 

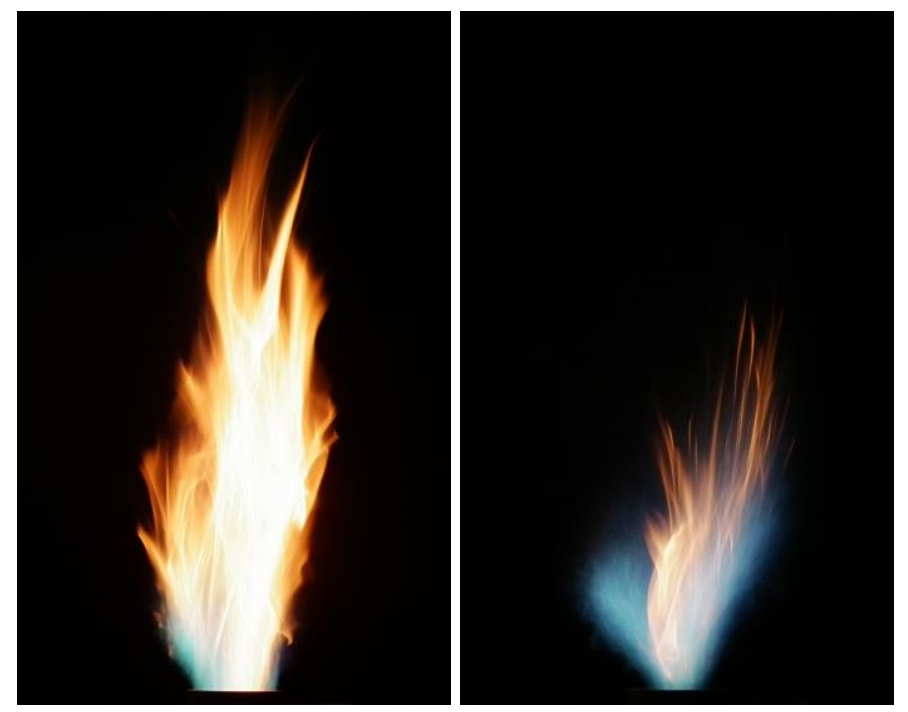

Fig. 5-Straight (left) and V-shaped flame (right). 

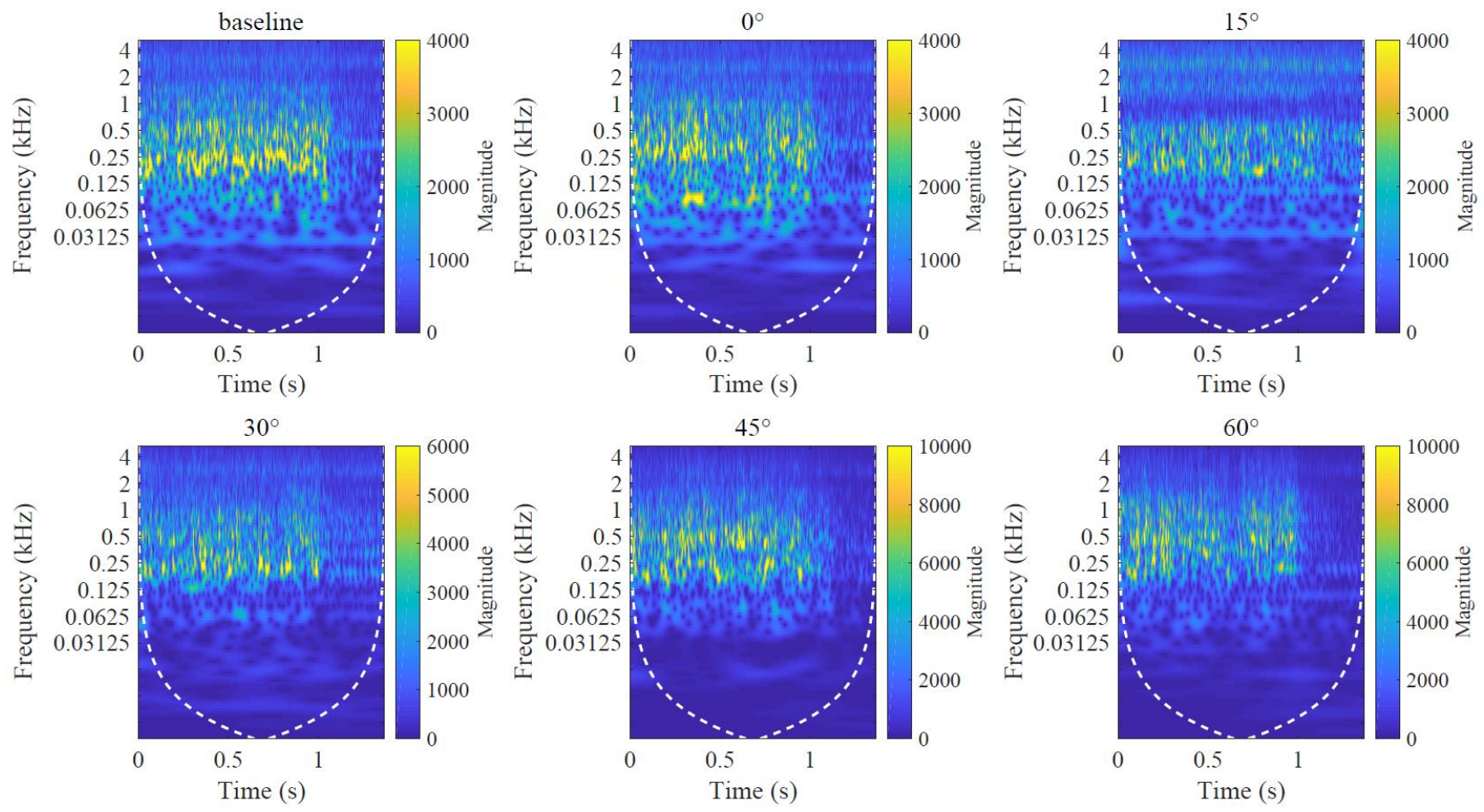

Fig. 6-CWT of the flame blowout at $p_{g}=0.3$ bar with various quarls. 

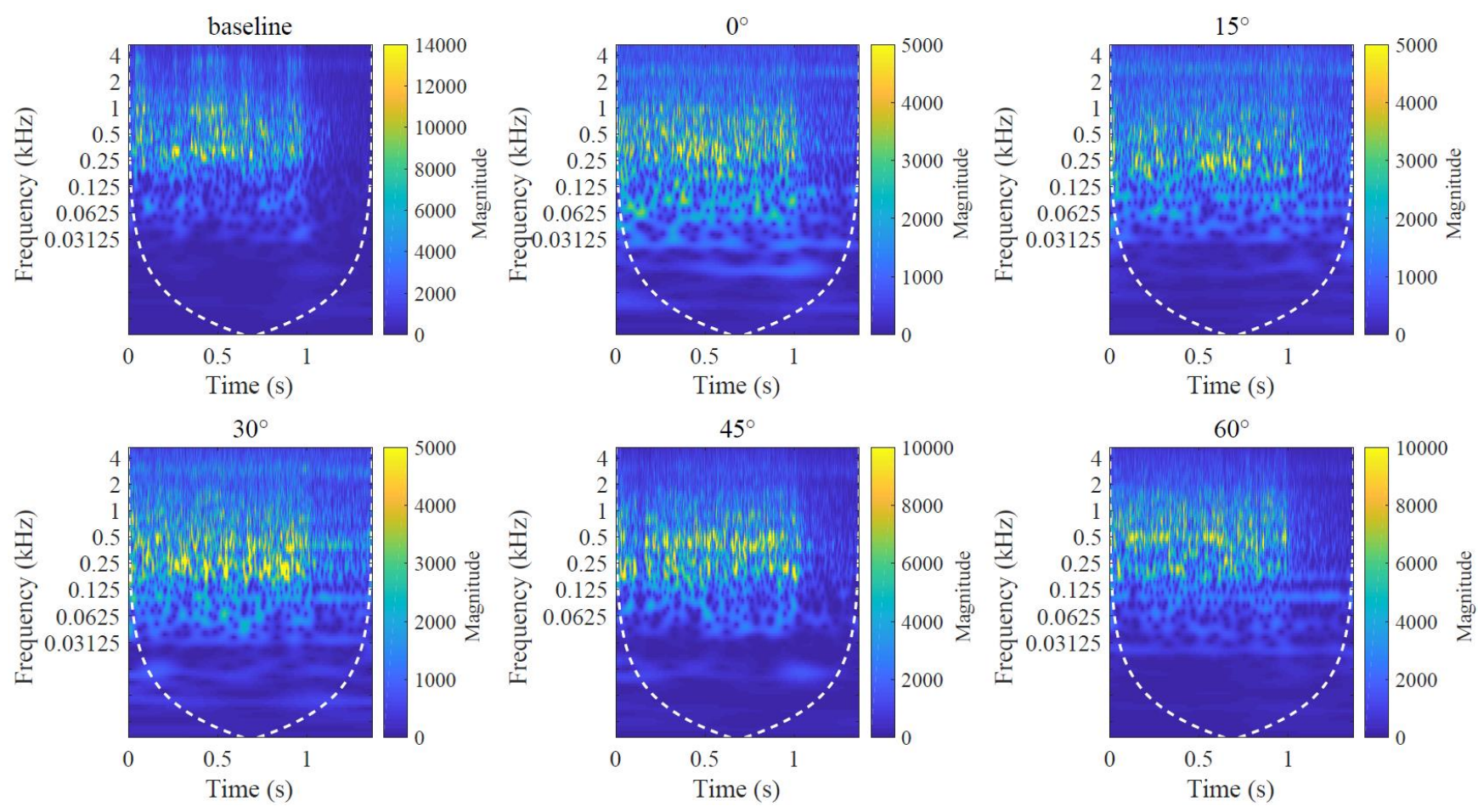

Fig. 7-CWT of the flame blowout at $p_{g}=0.6$ bar with various quarls. 

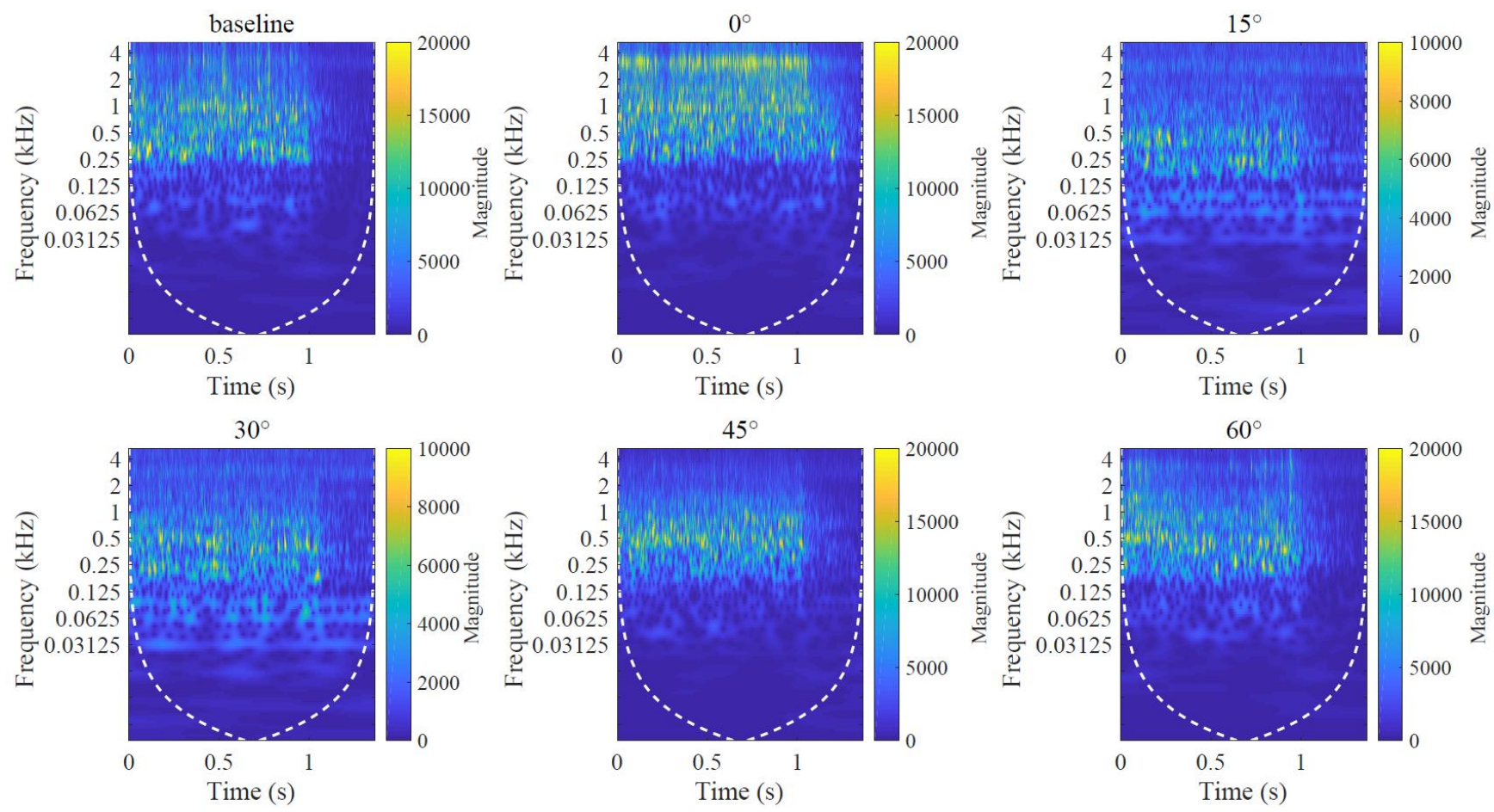

Fig. 8-CWT of the flame blowout at $p_{g}=1.6$ bar with various quarls. 